\title{
A CULTURA ESTÉTICA E A EDUCAÇÃO DO GOSTO COMO CAMINHO DE FORMAÇÃO E HUMANIZAÇÃO NA ÁREA DA SAÚDE
}

\author{
THE CULTURE OF AESTHETICS AND TASTE EDUCATION AS THE PATH FOR TRAINING AND \\ HUMANIZATION IN HEALTH
}

\section{LA CULTURA ESTÉTICA Y LA EDUCACIÓN DEL GUSTO COMO CAMINO DE FORMACIÓN Y HUMANIZACIÓN EN EL ÁREA DE LA SALUD}

\author{
Marlon Ribeiro da Silva ${ }^{1}$ \\ Jacqueline Sakamoto $^{2}$ \\ Dante Marcello Claramonte Gallian ${ }^{3}$
}

Resumo Partindo da candente discussão sobre humanização em saúde, este ensaio procura problematizar a abordagem sobre essa temática enfocando a necessária contribuição da 'teoria da cultura' e da 'educação do gosto'. Resgatando, numa perspectiva histórica e filosófica, os conceitos de Kultur e Bildung de Goethe e entendendo a formação como resultado da 'educação do gosto', este ensaio busca também pensar a humanização do profissional de saúde para além da implementação de políticas de treinamento técnico aplicadas no cotidiano do trabalho - também como experiência efetiva de uma formação pessoal que passa por uma experiência cultural.

Palavras-chave cultura estética; educação do gosto; formação; humanização; profissional de saúde.
Abstract Based on the hot-button discussion about humane health care, this essay aims to discuss the approach to the necessary contribution of the theory of culture and taste education. Upon bringing up, from a historical and philosophical perspective, Goethe's concepts of Kultur and Bildung and the understanding that training is a result of taste education, we seek to think of the humanization of health professionals beyond the implementation of technical training policies applied in daily work as an effective personal training experience that goes through a cultural experience.

Keywords culture of aesthetics; taste education; training; humanization; health professional. 


\section{Desumanização e humanização da saúde}

Para a compreensão do que consideramos ser a desumanização do profissional de saúde, é necessário nos situarmos historicamente no que diz respeito à relação das humanidades com os saberes relacionados à saúde, que em sua origem era uma ciência essencialmente humanística. A Antiguidade Grega apresentava um médico que deveria ser, antes de um naturalista ou biólogo, um humanista - um sábio que leva em consideração a integralidade humana ao fazer seus diagnósticos (Gallian, 2000).

Não somente na Antiguidade Clássica predominou a concepção humanística da medicina, mas também no Renascimento e no Iluminismo, em que diante das reformulações de diversas questões ideológicas e científicas, essa concepção continuou a ser afirmada. Mesmo no século XIX, com toda a sua pluralidade intelectual, as humanidades faziam parte dos saberes médicos, época em que surgiu a imagem romântica daquele ideal grego de médico - um médico constantemente atualizado no que tange aos avanços científicos tanto patológicos como farmacológicos, mas ainda assim um humanista, usando também seus conhecimentos literários, filosóficos e históricos ao fazer os diagnósticos (Gallian, 2000).

O médico estava inserido em diversas esferas da vida de seus pacientes, principalmente no que se referia à cultura. Porém, na virada do século XIX para o XX, com o desenvolvimento das análises laboratoriais e as descobertas no campo da microbiologia e dos medicamentos, esse desenvolvimento desencadeou uma modificação dos valores formativos do profissional de saúde, resultando no que consideramos ser a sua desumanização (Gallian, 2000).

Dessa forma, os avanços tecnológicos têm produzido peculiaridades no que se refere à prática e à formação do profissional de saúde. Ao passo que a tecnologia aperfeiçoa as técnicas necessárias para melhor execução da profissão, ela acaba se tornando finalidade, resultando no esquecimento de quem é o 'objeto' em questão, ou seja, o ser humano. Entendemos, assim, que essa supervalorização das ciências biológicas e dos avanços tecnológicos resulta na 'desumanização' do médico, em razão da tecnificação tanto de sua formação como da prática, que o leva, muitas vezes, a ignorar as questões humanísticas de seus pacientes - o que torna necessária uma formação mais abrangente (Gallian, 2000).

Essa reflexão nos leva a considerar que a supervalorização dos elementos técnicos característicos da biomedicina em detrimento dos conhecimentos 'humanísticos' desencadeia a desumanização da formação do profissional de saúde, tornando a questão da humanização desse profissional um tema atual e necessário.

Tendo em vista o desempenho do profissional de saúde e a subjetividade de sua atuação ante a população, o Sistema Único de Saúde desenvolve a Política Nacional de Humanização, segundo a qual se pretende desenvolver práticas de gestão e um modelo de atenção profissional humanizado. Para tanto, 
compreende-se a formação como algo que ocorre no próprio cotidiano do trabalho, buscando o desenvolvimento de processos relacionais baseados na multiprofissionalidade, na intersetorialidade e na interdisciplinaridade (Garcia, Ferreira e Ferronato, 2012).

Essa perspectiva de formação sugere que a humanização se dá no próprio agir profissional, na experimentação do trabalho, na articulação administrativa por parte da gestão e na colaboração entre os profissionais (Garcia, Ferreira e Ferronato, 2012) - concepção essa baseada no conceito de integralidade que sugere que a base para a formação desse profissional deve ser o próprio ambiente de trabalho. Logo, formação, nesse sentido, significa produção de realidade, razão pela qual não se dissocia da criação de modos de gestão do processo de trabalho. Portanto, nessa perspectiva, o trabalho tem papel formativo, pois é exercício de criação do humano, influenciando a visão de si mesmo e do mundo (Heckert e Neves, 2010).

Obviamente não negamos a importância do papel formativo do trabalho. Porém, é possível considerar que a prática profissional, por si mesma, proporcione essa experiência humanizadora, e que políticas administrativas levem o profissional a desenvolver essas competências, ou qualidades, relacionais? Como promover essas mudanças em uma medicina pautada no modelo biomédico se consideramos que a formação deve passar, também, pela reflexão ética (Rios, 2007)?

Consideramos que a humanização não pode ser simplesmente ensinada ou aprendida tecnicamente, tampouco entendida como processo de aprendizado moral ou mesmo ético. Ela é uma experiência pessoal, processual, contínua e, acima de tudo, cultural e estética.

Partindo desse princípio, buscaremos recuperar o papel da cultura e sua importância na formação e na humanização do profissional de saúde.4

\section{Cultura como forma de experiência educacional}

A modernidade, diante dos avanços do modo de produção capitalista e do consumismo, nos colocou diante do apogeu do que Teixeira Coelho (2001, p. 65) chama de "desculturalização do ensino". Não somente pelo crescimento da cultura de consumo, especialmente nos países em desenvolvimento econômico e industrial, mas principalmente pela mudança nos modelos educacionais resultantes de tal processo.

Nesse processo, até mesmo a arte passa a ser puro produto comercial.

O ensino não proporciona o que é chamado pelo autor de "experiência do difuso e do indeterminado". O sujeito é treinado a não mais sentir, não perceber o que aparentemente é inútil, por supor não ter valor científico ou comercial (Coelho, 2001). 
De acordo com Teixeira Coelho (2001), a necessidade de sentido e a cientifização do pensamento tornam o sujeito insensível ao 'difuso', ou seja, à possibilidade de pura e simples sensação, de experimentação e efeito. A educação deixou de estimular o sujeito a perceber e sentir de forma singular e independente da busca por valores utilitários de verdade. Em detrimento disso, ensina o sujeito a assimilar informações com sentidos dados. Mas é justamente na falta de explicação que muitas vezes o sujeito sente ou percebe algo que o toca e o forma, pela sensação estética.

Tendo a cultura estética como uma forma de experiência educacional, o sujeito é levado à ampliação e ao desenvolvimento da sua capacidade de sentir, criar sentido e desenvolver valores e singularidades de acordo com o que sentiu, produzindo uma cultura que vai ao encontro das suas necessidades interiores, ou seja, humanas.

Uma educação meramente informativa não tem o potencial de fazer o sujeito se encontrar consigo mesmo, afastando-o dos potenciais de sensação que lhe são atribuídos como humano, isto é, o sujeito não sente, apenas tem determinada informação e sentido sobre o que aconteceu ou conheceu.

O fenômeno de sentir sem atribuição a priori de valor de verdade, mas que pela percepção subjetiva ganha significado, possibilitando no sujeito o encontro consigo mesmo, denomina-se 'experiência do difuso' - quando essa pessoa se percebe diferente dos demais e com potencial de significar sensações e sentimentos de forma particular, porém não desvinculada da cultura produzida ao seu redor. Nesse sentido, a própria cultura do trabalho passa a ter um papel formativo mais significativo, pois o agir profissional ganha singularidade e propósito.

Teixeira Coelho nos sugere que a 'experiência do difuso' se dá a partir de um pensamento de tipo 'prismático', no qual se deve superar simples tentativas de determinar a experiência de forma precisa e significativa. As definições são importantes para o conhecimento científico e profissional, mas não significativas para a vida cotidiana. Essa experiência de relativização de significados, diante de uma experiência prismática e difusa causada por uma obra de arte, pode gerar no sujeito a aquisição de uma nova consciência. Dessa forma, afirma o autor:

(...) enquanto a educação não se livrar de todo propósito utilitário, ela continuará a ser apenas uma educação quase certamente filisteia, para dizer o menos, como uma educação incapaz de alcançar aquilo mesmo que ela equivocadamente se atribui (Coelho, 2001, p. 72-73).

É necessário uma cultura, ou seja, uma educação estética que motive o sujeito a ter uma experiência singular e única de sensações e criação de sentidos. Portanto, não é somente com a 'experiência do difuso' que alcançamos 
um pensamento prismático diante de determinada problemática em nossa vida; é fundamental, diante da diversidade de possibilidades de olhares sobre as coisas, o desenvolvimento do gosto - pois é este que nos leva ao que o autor chama de "experiência de ampliação da presença da esfera do ser" (Coelho, 2001, p. 76).

Considerando de forma crítica o papel formativo da cultura na educação do gosto, trazemos à tona as questões da cultura (Kultur) e da formação (Bildung) do sujeito e o respectivo papel da arte no processo educacional. Para isso, nos aproximamos da concepção clássica alemã desses conceitos.

\section{Cultura e formação em Goethe}

Johann Gottfried von Herder é considerado o primeiro a fazer reflexões a respeito da Kultur no contexto alemão. Seu pensamento influenciou o romantismo de forma relevante. Vemos nesse momento uma ideia que sugere a cultura como força criativa, singular e interior ao homem, que o leva à sua própria formação, sem dissociação da natureza, pois é onde sua história se realiza. Assim, o próprio sujeito toma posse dessa potência criadora, usando de sua inteligência e linguagem para criação da Kultur.

Entretanto, apesar de interior e pessoal, essa formação não é individualista, pois se realiza na natureza, ou seja, na cultura, em relação aos demais que o rodeiam. Assim, a realização da Bildung se dá em relação dialética com a Kultur. Para Herder, como nos mostra o filósofo alemão Rüdiger Safranski (2010, p. 28), não há “O homem", e sim “Os homens". Dessa forma, segundo Herder, o homem necessita viver em comunidade e com ela também se desenvolver individualmente. Vemos assim uma ideia de cultura que a sugere como força criativa, interior ao homem, que o conduz à sua própria formação, definida como 'estímulo de humanidade'. Nesse ponto chegamos ao conceito Bildung, que se refere à formação pessoal do homem em relação à diversidade da cultura como um todo (Safranski, 2010, p. 21-30).

O conceito Kultur se refere não somente a sua criação artística, mas também à identidade cultural e educacional. Esse termo é originário do adjetivo alemão kulturell, que seria traduzido para o português como 'cultivado', referindo-se à produção cultural humana. Esta é a compreensão de Kultur da burguesia criativa alemã em termos de identidade cultural em meados do século XVIII, compreensão que percebe a elevação da sociedade a um estágio superior, mas em razão da sua criação artística.

Nas palavras de Norbert Elias:

Pode-se dizer que no significado do termo alemão Kultur estava embutida uma predisposição não-política, e talvez mesmo antipolítica, sintomática do frequente 
sentimento entre as elites da classe média alemã de que a política e os assuntos do Estado representavam a esfera de sua humilhação e da falta de liberdade, ao passo que a cultura representava a esfera da sua liberdade e de seu orgulho (Elias, 1997, p. 122).

Vemos exemplos dessa concepção de Kultur no romance Werther, de Goethe (1971) - uma história que trata de um jovem burguês que decide morar em uma cidade pequena e acaba vivendo uma clássica história romântica.

Werther decide viver em uma cidade pequena, onde se apaixona por Carlota, mulher também de origem burguesa. Mas ela tem um noivo, que está em viagem de negócios. Nessa trama, o jovem Werther é um leitor de poesias e romances gregos e frequenta bailes populares. Goethe nos mostrará que a burguesia não está alheia à vida da corte, mas também não está inserida nela, o que faz essa burguesia, de certa forma, autônoma na produção de sua cultura.

Em um de seus passeios, Werther conhece um jovem recém-formado na universidade. Referindo-se a esse jovem, na carta de 17 de maio, ele diz:

quando soube que eu desenho muito e conheço o grego (duas coisas que são tidas aqui como fenomenais), procurou ligar-se a mim, desdobrando uma grande erudição (Goethe, 1971, p. 18).

Werther, apesar de reconhecer no rapaz determinada erudição, não lhe dá a devida importância, talvez em razão da arrogância do rapaz. Goethe pode estar nos mostrando em Werther um burguês culto, mas ao mesmo tempo gentil e próximo dos populares, muito sensível às necessidades das classes menos favorecidas. Em diversos trechos do romance, vemos Werther dando moedas às crianças e a senhoras viúvas.

A partir desse quadro podemos observar uma importante característica da ideia de Kultur, que é o afeto. Werther diz em sua carta de 15 de agosto: "A coisa mais certa deste mundo é que o afeto, somente, torna o homem necessário" (Goethe, 1971, p. 68). O afeto é apresentado como o mais importante sentimento humano.

Em contraposição à importância dada por Werther ao afeto, podemos observar claramente as suas críticas feitas contra a cultura da corte em defesa da Kultur. Essa ideia é clara na carta de 8 de janeiro de 1772, quando ele diz: “Que gente esta, cuja alma está inteiramente amarrada à etiqueta, aplicando, durante anos, todos os seus pensamentos e esforços a manter-se rigidamente à mesa" (Goethe, 1971, p. 84).

Percebemos, assim, que nesse ambiente revelado por Goethe em seu romance, vemos o florescer do conceito de Kultur, não sua criação, mas a profunda discussão e a formulação de valores conceituais, tendo como base as críticas à hipocrisia da cultura da corte e sua etiqueta tradicional. Pois, na 
Kultur, a atenção deve-se voltar para a formação interior do homem, em detrimento da simples postura aparente externa - o que nos remete ao conceito de Bildung.

Bildung é um conceito alemão que nos sugere reflexões nos sentidos mais profundos do ser humano, levando-nos a considerá-lo de forma integral, emocional, afetiva, intelectual e espiritual. Partindo da ideia da multiplicidade cultural, segundo os valores do conceito de Kultur, Herder e depois Goethe nos sugerem uma formação integral do ser humano. Dessa maneira, o conceito de Bildung se apresenta "enquanto teoria da socialização, processo complementar ou interação entre o eu e o mundo, o indivíduo particular e a sociedade" (Mazzari, 1999, p. 74). Bildung é a formação do homem, e esta só é possível se relacionada à cultura, como no caso do conceito Paideia na filosofia grega (Jaeger, 2001).

No romance Os anos de aprendizado de Wilhelm Meister (Goethe, 2006), identificamos essa preocupação no que diz respeito à formação pessoal partindo da cultura, considerando assim a questão política como subsequente da formação cultural e moral pessoal.

Essa perspectiva de cultura sugere a realização da formação pessoal nos âmbitos da experiência da arte, como mostra o referido romance goethiano. Quando Wilhelm, o personagem principal da história, manda uma carta para seu amigo Werner, um típico burguês envolvido com questões comerciais de sua família, ele diz, criticando suas pretensões comerciais:

De que me serve fabricar bom ferro, se meu próprio interior está cheio de escórias? E de que me serve também colocar em ordem uma propriedade rural, se comigo mesmo me desavim? (Goethe, 2006, p. 284).

Na mesma carta, em contraponto a esse ideal comercial, Wilhelm diz para Werner:

Pois bem, tenho justamente uma inclinação por essa formação harmônica de minha natureza, negada a mim por meu nascimento (...). Some-se a isso a minha inclinação pela poesia e por tudo quanto está relacionado a ela, e a necessidade de cultivar meu espírito e meu gosto (Goethe, 2006, p. 286).

A ideia de 'cultivar o espírito' está diretamente relacionada à conceituação de Kultur - na qual vemos a preocupação de Goethe com a necessidade de uma formação pessoal profunda que resultaria no desenvolvimento cultural de toda a nação.

Esses são conceitos que não só percebem a necessidade da formação do povo, mas também como esta se dá. Com essa mentalidade, Goethe escreveu Os anos de aprendizado de Wilhelm Meister (Goethe, 2006), formando assim 
o gênero literário posteriormente chamado de Bildungsroman (romance de formação) (Maas, 2000).

Por essa razão, consideramos que ao estudar uma obra literária clássica nos é possível aprender, por meio da obra ou do autor em questão, não somente características culturais de uma época, mas também valores conceituais ou morais, tanto quanto anseios, emoções, sentimentos, afinidades ou outra característica comum à vida humana. Além disso, os estudos literários, ou baseados em literatura, têm o potencial de influenciar o ser humano no que tange ao desenvolvimento dos potenciais que lhe são próprios, ou seja, a experiência estética da cultura.

Vemos no romance em questão que Bildung é um conceito que nos sugere uma educação que parte de experiências de vida, de tal forma que leve à formação pessoal. O romance Os anos de aprendizado de Wilhelm Meister (Goethe, 2006) pode colaborar para nossa reflexão, considerando-se que, além de ser um clássico que trata da formação pessoal de seu personagem, é um livro que carrega uma proposta conceitual e ideológica humanista clara - ou seja, o romance carrega uma proposta teórica e filosófica no que se refere à formação pessoal humana. Dessa forma, podemos perceber como Goethe pensava a formação integral do ser humano.

Marcus Mazzari (1999) nos mostra que a questão da formação do indivíduo quanto ao desenvolvimento de suas potencialidades é tema central no romance, sem deixar de considerar as condições históricas dadas. Assim, podemos observar no romance como Goethe entende a formação integral diante de determinada realidade histórica, o que nos mostra uma educação coerente com a realidade da vida, ou seja, não alienadora.

Tendo em vista que nosso objetivo é pensar a formação educacional, que por sua vez está inserida na sociedade capitalista, como destaca Goethe em seu romance - "Não cabe perguntar: 'Que és tu?', e sim: 'Que tu tens?'” (Goethe, 2006, p. 285) -, o romance se mostra literária e teoricamente coerente com o que propomos à reflexão. Pois, no romance, Wilhelm Meister não aspira somente ao desenvolvimento pleno de suas potencialidades, mas também a uma integração com a sociedade a que pertence.

Outra característica importante que nos chama a atenção no romance é a relativização da formação individual do ser humano. Goethe (2006, p. 523) afirma: "Só todos os homens juntos compõem a humanidade; só todas as forças reunidas, o mundo". Essa concepção de humanidade está em Goethe sob a influência de Herder, como já vimos. Dessa maneira, o conceito de Bildung no romance referido é importante para o nosso objetivo ao se afirmar como teoria de socialização e formação (Mazzari, 1999, p. 74). Como afirma Lukács (2006, p. 604): “Os anos de aprendizado de Wilhelm Meister é um romance de educação: seu conteúdo é a educação dos homens para a compreensão prática da realidade." 
Partindo dessa compreensão dos conceitos de cultura e formação, de acordo com o referencial goethiano, apontamos para a necessidade de uma educação estética, na qual o uso da arte passa a ser o caminho metodológico para a realização da formação educacional do sujeito.

Essa experiência de educação pela cultura, como sugerida pela literatura goethiana, pode ser entendida - como nos sugere Teixeira Coelho (2001, p. 66) - ainda como "ampliação da esfera da presença do ser". Esta se dá em razão do efeito estético causado pela arte de acordo com a complexidade e o desenvolvimento do gosto e percepção do sujeito, percepção essa nomeada por Teixeira Coelho como "a experiência do difuso e do indeterminado".

É na experiência da cultura como um todo e no desenvolvimento do gosto singular que o humano tem uma percepção estética que pode causar um 'efeito prismático'. Ou seja, a arte tem o potencial de afetar pelo sentimento e sensibilidade os afetos e a percepção do sujeito (Coelho, 2001), possuindo assim um efeito formativo. No entanto, para que essa experiência seja possível, o sujeito precisa desenvolver e educar seu gosto.

Assim, a formação é contínua, e em constante relação com a cultura e a educação do gosto.

\section{A educação do gosto como caminho formativo}

Já vimos neste trabalho como Goethe manifesta em suas obras sua percepção de educação pautada na educação do gosto. De acordo com essas ideias, vemos também no pensamento de Teixeira Coelho que a 'ampliação da esfera da presença do ser' se dá de acordo com o conhecimento do diverso e o desenvolvimento do gosto, em que:

O gosto, num sentido mais abrangente, é a faculdade de discernir características ou qualidades de objetos e fenômenos. Mais especificamente, é a vantagem de descobrir com sutileza e presteza a medida do prazer que cada coisa deve dar aos homens (...) gosto como sendo aquilo que, independente de ser bom ou mau, correto ou não, liga as pessoas a uma coisa, pelo sentimento (Coelho, 2001, p. 76).

Teixeira Coelho (2001) nos sugere a busca pelo gosto como um processo constante, que leva o sujeito à procura de novidades, a determinada ampliação de perspectivas a respeito do mundo. Essa constante busca do conhecimento da diversidade pode levar o sujeito ao encontro de si mesmo, mas também pode causar uma experiência de encontro com 'o outro'.

$\mathrm{O}$ autor nos mostra que, segundo Montesquieu, existem dois tipos de gosto, o natural e o adquirido. O gosto natural é imediato, basta que surpreenda. Já o gosto adquirido é resultado de um desenvolvimento por meio do 
conhecimento (Coelho, 2001). Esses dois tipos de gosto se desenvolvem mutuamente e formam o sujeito à medida que o gosto natural leva ao conhecimento de si e o gosto adquirido amplia a experiência e a perspectiva de mundo.

O exercício de ampliação dos gostos, tanto natural quanto adquirido, segundo nos é sugerido, pode levar o sujeito à “ampliação da esfera da presença do ser" na medida em que ambos se influenciam e se completam (Coelho, 2001, p. 81).

Essa perspectiva sobre o gosto somada à concepção kantiana (Kant, 1993), que o sugere como a capacidade de "julgar o belo" (Coelho, 2001, p. 83), nos permite, em associação aos valores de Bildung e Kultur, pensar a formação educacional do sujeito mediante a experiência de educação do gosto, partindo de uma experiência cultural estética, do conhecimento do diverso e de afeto ao mundo - ou seja, a cultura como um todo.

Se voltarmos ao romance Os anos de aprendizado de Wilhelm Meister (Goethe, 2006), podemos perceber essa concepção apresentada por Goethe, quando o personagem Wilhelm, ao ser apresentado às obras de Shakespeare, diz o seguinte:

(...) não lembro de nenhum outro livro, ser humano nem qualquer acontecimento da vida que tanta impressão me tenha causado quanto essas peças magníficas que, graças à sua bondade, pude conhecer. Parece obra de um gênio celestial, que se aproxima dos homens para lhes dar a conhecer a si mesmos de maneira mais natural (...) - Quisera - replicou Wilhelm - poder revelar-lhe tudo o que se passa agora dentro de mim. Todos os presságios em relação à humanidade e a seu destino, que me acompanhavam desde pequeno, sem mesmo adverti-los, encontro-os realizados e desenvolvidos nas peças de Shakespeare (...) Esses olhares ligeiros que lancei no mundo de Shakespeare me instigam, mais que qualquer outra coisa, a seguir adiante, a progredir com maior rapidez no mundo real, a misturar-me no fluxo dos destinos que lhes estão reservados (Goethe, 2006, p. 194-195).

Nesse trecho do romance, vemos o exemplo do efeito estético de que estamos tratando neste trabalho, segundo o qual, ao conhecer uma obra de arte que o tocou, Wilhelm identifica em si mesmo impressões tanto naturais quanto externas, em que além de se perceber, se dispõe e se anima para prosseguir a vida.

Logo, dialogando com os valores de cultura e formação no referencial alemão visto em Goethe, a educação do gosto se dá em relação ao todo cultural e na identificação com ele. A 'ampliação da esfera do ser' num campo pessoal.

A formação ocorre na relação entre o conhecimento e a experiência difusa e prismática de um particular (por exemplo, um quadro, um livro, uma música) diante de um todo cultural e seus significados. Esse diálogo entre a construção e a desconstrução de significados leva o sujeito ao desenvolvi- 
mento de si mesmo sem estar alheio ao todo que o rodeia - como mais uma vez fica exposto por Goethe em seu romance, quando um dos personagens responsáveis pela formação de Wilhelm diz-lhe o seguinte:

É bom que o homem que pela primeira vez entra no mundo faça uma grande ideia de si próprio, pense em obter-se muitas vantagens e procure fazer todo o possível; mas quando sua formação atinge um certo grau, é vantajoso que aprenda a se perder numa grande massa, aprenda a viver para os outros e a se esquecer de si mesmo numa atividade apropriada ao dever. Só então aprende a conhecer a si mesmo, pois é a ação que verdadeiramente nos compara aos outros (Goethe, 2006, p. 469).

Assim, a formação é causada pela relação do conhecimento de si, por meio do desenvolvimento do gosto e da ação em relação ao mundo que o rodeia.

Porém, essa educação só pode ser alcançada mediante uma educação estética, em que a arte é o caminho. Essa mesma concepção aparece no pensamento de Friedrich Schiller (2009) - amigo e colaborador de Goethe e diretamente influenciado pelo filósofo Immanuel Kant - ao afirmar que sem a arte o homem seria o mais egoísta dos animais e, apesar da disposição para a liberdade, um escravo dos sentidos.

Schiller nos sugere como a arte e o belo têm esse efeito formativo, quando diz:

Assim como uma apresentação plena de gosto convida ao pensamento e ajuda a promover o conhecimento da verdade, porque ela mesma forma uma matéria para a sensibilidade a partir de conceitos abstratos, assim também o gosto ajuda a promover a eticidade do agir ao fazer com que as prescrições morais da razão concordem com o interesse dos sentidos e ao transformar o ideal da virtude num objeto de inclinação (Schiller, 2009, p. 132).

Somente a arte tem esse papel formativo, pois o gosto é que rege as vontades humanas, mas não por meio de leis e sim de sentimentos (Schiller, 2009).

Logo, é mediante toda essa concepção de cultura como forma de experiência estética e educação do gosto que sugerimos as humanidades como caminho metodológico de formação e humanização do profissional de saúde.

\section{Conclusão: a formação humanística do profissional de saúde}

A formação humanística supõe uma prática profissional no âmbito da saúde centrada na pessoa, e não na doença. Dessa forma, é necessário mais que 
técnicas médicas avançadas, posições políticas ou concepções filosófico-sociais a respeito da humanidade. O essencial está no conhecimento profundo e estético da realidade existencial humana.

Gregório Marañón se refere ao saber humanístico como 'uma das cinco fontes do saber médico' (Gallian, 2002), pois é por meio das obras de arte que o profissional de saúde desenvolve e aprofunda sua formação pessoal, no que tange à sua humanidade - o que resulta, por exemplo, no desenvolvimento do afeto e da sensibilidade. Uma perspectiva humanista da formação do profissional de saúde nos sugere a valorização do saber humanístico, que tem como fonte a arte (Gallian, 2002).

Nesse sentido, valorizando o saber humanístico, podemos pensar a humanização do profissional de saúde, à medida que buscamos desenvolver integralmente as potencialidades humanas do sujeito por meio da sensibilidade trazida pela experiência da cultura. Como nos mostra Irene Goldschmidt, trazendo a questão da cultura para a formação do profissional de saúde:

A ação educativa deve incidir também no campo cultural, nas formas de pensar, ver e sentir, para que os novos conhecimentos venham a se integrar ao universo gnosiológico preexistente, transformando-o em sua totalidade (Goldschmidt, 2012, p. 63).

Assim, a cultura estética possibilita a transformação da consciência do sujeito, o que resulta na mudança de sua prática profissional. Logo, a cultura tem potencial humanizador, pois

a verdadeira obra de arte tem um incrível poder mobilizador. Possui a capacidade de criar empatia, gerar crises, provocar mudanças, que são essenciais para o processo de humanização da pessoa que se realiza enquanto indivíduo, seja ela um médico, um estudante de medicina, um técnico, um engenheiro ou o que for (Gallian, 2002, p. 49).

A literatura, por exemplo, não somente apresenta fatos em relação à vida, mas nos sugere sentido (Quintás, 2000; Compagnon, 2009) - sentido esse que, se explorado e trabalhado racionalmente, pode sensibilizar o leitor, possibilitando o processo de humanização de sua prática. Dessa forma, entendemos que a experiência estética da cultura, causada por meio de obras de arte, ou seja, das humanidades, tem o potencial formativo e humanizador, podendo assim ser base teórica para humanização na formação do profissional de saúde. 
Resumen Con base en la candente discusión sobre humanización en salud, este ensayo busca problematizar el enfoque sobre la necesaria contribución de la teoría de la cultura y de la educación del gusto. Mediante el rescate, desde una perspectiva histórica y filosófica, de los conceptos Kultur y Bildung de Goethe y la comprensión de que la formación es el resultado de la educación de gusto, se buscan pensar en la humanización del profesional de salud más allá de la implementación de políticas de capacitación técnica aplicadas al trabajo cotidiano, como una experiencia efectiva de una formación personal que pasa por una experiencia cultural.

Palabras clave Cultura estética, educación del gusto, formación, humanización, profesional de la salud.

\section{Notas}

1 Universidade Federal de São Paulo, São Paulo, Brasil.

Mestre em Saúde Coletiva pela Escola Paulista de Medicina da Universidade Federal de São Paulo.<marlon.educ@gmail.com>

Correspondência: Rua Visconde de Guaratiba, 383, CEP 04125-040, Vila Firmiano Pinto, São Paulo, SP, Brasil.

2 Universidade Federal de São Paulo, São Paulo, Brasil.

Doutoranda em Saúde Coletiva na Escola Paulista de Medicina da Universidade Federal de São Paulo.<jacqueline.sakamoto@gmail.com>

3 Universidade Federal de São Paulo, São Paulo, Brasil.

Doutor em História Social pela Faculdade de Filosofia, Letras e Ciências Humanas da Universidade de São Paulo. <dante.cehfi@epm.br>

4 Este trabalho representa parte da reflexão teórica do projeto de pesquisa intitulado "As patologias da modernidade e os remédios das humanidades: investigação e experimentação", em realização no Centro de História e Filosofia das Ciências da Saúde (CehFi) da Escola Paulista de Medicina da Universidade Federal de São Paulo (EPM-Unifesp), com apoio e financiamento da Fundação de Amparo à Pesquisa do Estado de São Paulo (Fapesp, 2010/50448-0). Seu objetivo central é investigar o papel das humanidades como meio de formação e humanização do profissional de saúde. 


\section{Referências}

COELHO, Teixeira. A cultura como experiência. In: RIBEIRO, Renato. Humanidades: um novo curso para a USP. São Paulo: Edusp, 2001. p. 65-101.

COMPAGNON, Antoine. Literatura para quê? Tradução de Laura Taddei Brandini. Belo Horizonte: Editora UFMG, 2009.

ELIAS, Norbert. Os alemães: a luta pelo poder e a evolução dos hábitos nos séculos XIX e XX. Tradução de Álvaro Cabral. Rio de Janeiro: Jorge Zahar, 1997.

JAEGER, Werner. A formação do homem grego. Tradução de Artur M. Parreira. São Paulo: Martins Fontes, 2001.

GALLIAN, Dante. A (re)humanização da medicina. Psiquiatria na Prática Médica, São Paulo, v. 33, n. 2, 2000, p. 5-8. Disponível em: $<$ www.unifesp.br/dpsiq/polbr/ppm/especial02a. htm>. Acesso em: 4 jun. 2012.

As humanidades e o saber médico. Notandum, São Paulo, ano V, n. 9, p. 47-50, 2002. Disponível em: <www.hottopos.com/notand9/ dante.htm>. Acesso em: 4 jul. 2012.

GARCIA, Maria Alice A.; FERREIRA, Fernanda P.; FERRONATO, Fernanda A. Experiências de humanização por estudantes de medicina. Trabalho, Educação e Saúde, Rio de Janeiro, v. 10, n. 1, p. 87-106, 2012.

GOETHE, Johann. Werther. 1. ed. Tradução de Galeão Coutinho. São Paulo: Abril Cultural, 1971.

Os anos de aprendizado de Wilhelm Meister. 2. ed. Tradução de Nicolino Simone Neto. São Paulo: Editora 34, 2006.

GOLDSCHMIDT, Irene L. O teatro de Augusto Boal e a educação profissional em saúde. Trabalho, Educação e Saúde, Rio de Janeiro, v. 10 n. 1, p. 61-69, mar./jun. 2012.
HECKERT, Ana Lúcia C; NEVES, Cláudia A. B. Modos de formar e modos de intervir: quando a formação se faz potência de produção de coletivo. In: BRASIL. Ministério da Saúde. Secretaria de Atenção à Saúde. Política Nacional de Humanização. Cadernos HumanizaSUS. Volume 1. Formação e intervenção. Brasília, DF: Ministério da Saúde, 2010. p. 13-28 (Série B. Textos Básicos de Saúde; Cadernos Humaniza SUS, v. 1)

LUKÁCS, George. Posfácio. In: GOETHE, Johann. Os anos de aprendizado de Wilhelm Meister. 2. ed. Tradução de Nicolino Simone Neto. São Paulo: Editora 34, 2006.

KANT, Emmanuel. Observações sobre o sentimento do belo e do sublime. Tradução de Vinícius de Figueiredo. Campinas: Papirus, 1993.

MAAS, Wilma. O cânone mínimo: o Bildungsroman na história da literatura. São Paulo: Unesp, 2000.

MAZZARI, Marcus. Romance de formação em perspectiva histórica. São Paulo: Ateliê Editorial, 1999.

QUINTÁS, Alfonso. El analise literario y su papel formativo. Corvenit Internacional, 1, 2000. Disponível em: <www.hottopos.com/ convenit/lq1.htm>. Acesso em: 6 ago. 2012.

RIOS, Izabel C. Ser e fazer diferente... É possível provocar o desejo? Interface: Comunicação, Saúde, Educação, Botucatu, v. 11, n. 23, p. 619-635, 2007.

SAFRANSKI, Rüdiger. Romantismo, uma questão alemã. Tradução de Rita Rios. São Paulo: Estação Liberdade, 2010.

SCHILLER, Friedrich. Cultura estética e liberdade. Tradução de Ricardo Barbosa. São Paulo: Hedra, 2009.

Recebido em 27/11/2012

Aprovado em 17/11/2013 